\title{
Senior Scholars: Is The Brave New World Of On-Line Publishing For Us?
}

\author{
Judith A. Laux, Colorado College, USA
}

\begin{abstract}
${ }^{1}$
Active academics whose careers span several decades have witnessed a changing landscape for disseminating their research and scholarship. As technology changes, the ability to share research increases exponentially, and the choice of outlets becomes more intricate. This article discusses the role of scholarship in the lives of seasoned college educators, describes some of the major changes in the world of scholarly publication, and speculates about how this evolving environment might change our publishing strategies. Finally, the article offers advice to senior faculty members for playing a more active role in the future of knowledge sharing.
\end{abstract}

Keywords: Open Access; Online Publishing; Academic Publishing; Scholarship

\section{INTRODUCTION}

$\mathrm{n}$ an effort to guide late-career academics who wish to participate more forcefully in laying the
foundation for future researchers, the current article poses a number of questions: Why do we engage in research? What mechanisms do we have for sharing research and scholarship? What changes are unfolding that might alter the way we approach research and scholarship? How do these changes influence our strategy to circulate our scholarly products? And, finally, what actions might these changes warrant for best furthering knowledge in our academic areas? Each of these questions should force introspection about why we dedicate ourselves to scholarship, why we find it important to present our work to others, how the channels for distribution have changed, and how the distribution of our work (and that of our younger colleagues) might evolve in the future.

\section{Why Devote Time and Effort to Research?}

In response to the first question - "why engage in research?"- new Ph.D.s will say "to get tenure!" because publication is required at most institutions to become the "seasoned" scholar. Even liberal arts institutions such as my own institution (Colorado College) place a premium on young scholars' ability to add to the knowledge of their discipline in a peer-reviewed and public fashion. And the journal or outlet matters; empirical, data-driven, discovery-based research represents the currency of top-ranked journals, and new faculty are expected, almost universally, to aim high. However, for those of us who are post-tenure, who lack graduate programs and assistants, who might have engaged in scholarly discourse later in the career, or who do not have co-authors or access to expensive databases, research must have a broader purpose.

Most good teachers will justify scholarship, especially research that keeps us in touch with our own subfields, on the basis that we should know as much as possible about our own areas so that we stay abreast of the unanswered questions. This helps in our student-teacher collaborative research, if that's an expectation at your institution as it is at mine, and it enhances our ability in the classroom. Students want to know the relevance of the theory covered in a given course, and the theory drives the research, so professors should be expected to participate

\footnotetext{
${ }^{1}$ The current article represents a revised and expanded version of a keynote address entitled "Scholarship and the Academic 'Lifer"” presented at the Clute Institute International Academic Conference, Paris, France, in June 2013, published in the proceedings of that conference, presented at the 2014 Academic Conference in Las Vegas, and published in a revised form in the proceedings of that conference.
} 
in scholarship that challenges and improves those theories. In turn, students should be exposed to the best, most approachable literature, even at the undergraduate level, if they are to glimpse the possibility of joining the professoriate as their own choice of profession.

One can view research and scholarship as two different things, as research asks specific questions, typically those that can be investigated empirically, while scholarship involves something more general that is derived from the summation of the research. LaPidus [p. 5 of online version, Bookshelf ID: NBN45336, 1998] poses the question: "Scholarly Research: Oxymoron, Redundancy, or Necessity?" and he concludes that "Research is something you do; scholarship is the way you think about it... [R]esearch is a process for obtaining information, and scholarship is a process for converting information into knowledge." So, while we might research with publication as the end pursued, we engage in scholarship to offer some greater knowledge to our students and our colleagues. Boyer, in "Scholarship Reconsidered" [1990, p. 16] puts it this way: "Surely, scholarship means engaging in original research. But the work of the scholar also means stepping back from one's investigation, looking for connections, building bridges between theory and practice, and communicating one's knowledge effectively to students." Similarly, Henson [2001, p. 768] suggests that non-empirical work is worthwhile, because "much knowledge can be gained by both the writers and readers of articles that report on the ideas of others, even though no original empirical research study is involved." This provides a perfect segue to the next justification for maintaining an active research agenda - fostering enthusiasm.

For the academic "lifer," perhaps the most important reason to investigate those unanswered questions is to keep us mentally alive and intellectually stimulated. Teaching should always be stimulating, of course, even if we teach the same courses year after year, because the students are always different, and thus the dynamic changes. But we all know that our syllabi do not change of their own volition. Something has to inform us that improvement is warranted, and quite often that "something" springs from our scholarly engagement outside the classroom. As a professor at CC for more than three decades now, I know investigation keeps my torch lit. I use some of that work in courses, and students often remark on my enthusiasm for the fields of accounting and finance.

A fourth reason for staying active in our scholarship results from keeping our own torches lit-we can light the torches of others - our students and colleagues as well as scholars at other institutions. After all, part of our job as academics is to create intellectual capital, the very product of research and scholarship, and that capital has no value unless it's shared, regardless of the outlet. So, how do we transmit that energy? How do we disseminate our scholarship? Those queries form the basis of the next big question, an important one, since the forums can (and should) change over the span of a career.

\section{Through What Mechanisms Do We Share Our Scholarship?}

Putting our research products before others can take a number of forms and appear in a wide variety of venues. In the past, this exchange of ideas often has taken the form of symposia or informal discussions among interested colleagues, but in a world of higher expectations for scholarly production, we must move far beyond our own institutions. Still, if we're lucky and funding and incentives are provided, we can share our research, even our unrefined research, through seminars and symposia at our own institutions. It's nice to have the opportunity to try out new ideas at home-in front of the friendly audience. When it works, it's a beautiful thing. But sometimes we lack the funding or support to coordinate these exchanges, and if our departments are so specialized that we stand alone in our subfield, the constructive feedback might be lacking. Typically, however, we can benefit from nudging our work in its early stages towards a familiar audience, and we can find a way to make it a collaborative endeavor.

Collaborative arrangements with nearby institutions can be even more productive-a kind of "exchange program" for professors. This method of sharing ideas and receiving input takes a little more coordination, time, energy, and perhaps more funding, but it can also result in higher quality feedback, as we can profit from the knowledge of others more familiar with our subfields and those unanswered questions. As we share and collaborate with our neighbors, we really take a mini-step toward sharing with broader audiences, such as those we find at conferences, another venue for distributing our work. 
Conference presentations force us to bring our scholarly products to an even higher stage of completion. Furthermore, if the conferences are organized to group papers by meaningful categories or topics, the resulting discussions can inspire us. These sessions show us that others see the value of questions in our area, approach these questions differently, and offer diverse recommendations for investigation, policy change, and classroom treatment. The unfortunate aspect of conference presentations is that they give such a limited time in which our audiences can assimilate and reflect on our research that, typically, we can expect only feedback that enhances our scholarship rather than refines our research. But, even then, the conference interaction allows us to make connections with others in our field, connections that can lead to further collaboration. Often, early versions of full papers are published in conference proceedings and thus become available for later review and reflection by our peer audience.

Finally, journal submission mandates the peer review that constitutes the "high bar" for scrutiny of our work. Through this process, we usually see a set of narrative comments (including strengths and weaknesses), the manuscript's acceptability for the journal, and a recommendation ranging from "accept as is" to "revise and resubmit" to the always feared "reject." Since, in many cases, we have pursued the other mechanisms for disseminating our work and incorporated the accompanying feedback, as scholars we hold the view that this is a finished piece and must steel ourselves against the rejection that can come. In "Contributing to the Profession in Meaningful Ways" [2002], Spooner, Spooner, and Karvonen give good advice to authors facing reviewers' recommendations (a must read for young scholars), and the authors even turn the tables and offer suggestions to reviewers themselves about how to make the recommendations as constructive as possible.

Regardless of the outlets selected for our scholarly labors, at some point, we must ask the hard question: Why am I doing this? Is it for job security or some higher purpose? To paraphrase Henson [2001], writing to be published is admirable, but writing as part of professional development is at least as important. Of course, research that promotes the greater good of society would be the most fulfilling of all. For example, I have a colleague who refuses to invest his time in scholarly pursuits that lack connection to societal wellbeing or, as he puts it, the research must "have significant potential to make a difference in contexts beyond the annals of refereed literature" [Parco, "Research Principles and Goals," 2013]. My own work in financial management and accounting theory is designed to teach students about ethical challenges in a theoretical context, with the expressed goal of giving next-generation financial managers and accountants a framework within which to consider (and defend) the ethical ramifications of their actions. So what changes are unfolding that might influence how we research and pursue our scholastic development?

\section{The Changing World of Academic Research}

The world of academic publication has witnessed a number of changes in the last three decades, and I will discuss a few of the more obvious. Certainly, in the business area, the questions investigated through empirical research have become more specific, incorporated larger databases, employed more sophisticated methodologies, and required more specialized knowledge for interpretation. In addition, more work now is co-authored in virtually all fields of economics and business. The number of outlets has increased dramatically, and open access and its myriad issues now confront us. And this strange new world of digital information invites a whole host of questions for us as researchers:

\footnotetext{
- What sources can I trust?

- When and how do I cite these sources?

- How do I separate the important from the unimportant?

- Who is the real expert on this question?

- $\quad$ Where do I publish my work?
}

The road is a tough one, and certain disciplines offer track records that can make authors balk. Often we must consider new avenues for what we believe is worthwhile, albeit not mainstream, scholarship. 


\section{The Challenges of Publishing in Accounting}

Allow me to elaborate a bit on the difficulty of becoming well-published in my primary area of accounting (with finance showing similar patterns). Statistics present a dismal picture. In an article devoted to describing two key realities of the academic accounting labor market (rewards for solid research and the shortage of accounting Ph.D.s), Hermanson [2008, pp. 56, 60] offers a good overview of the statistics of others as he makes the case that "relatively few accounting academics publish a large number of articles in refereed accounting journals" and that "it is more difficult for accounting academics to publish in major journals than it is for faculty in other business disciplines." He cites the following statistics:

- $\quad$ Zivney et al. [1995, p. 1] — “The average publishing accounting faculty member publishes about one article every three years in one of the 66 journals studied. Less than ten percent of the publishing faculty average one article per year in any of the 66 journals."

- Hasselback et al. [2003] - “...only 20 percent of accounting faculty have published more than five papers in the top 40 journals in their career, and 36 percent have no publications in the top 40 journals."

- $\quad$ Swanson [2004, p. 224] - “....the proportion of doctoral faculty publishing a major article is 1.4 to 2.4 times greater in the other business disciplines than in accounting."

Hermanson also encourages an investigation of other works bearing statistics about publication success. For example, Englebrecht et al. [1994] and Glover et al. 2006 [and 2012] look at the publication history of promoted accounting faculty over three different time spans-1987-89, 1995-2003, and 2004-2009. In the first work, several observations relate directly to the current article. First, publication rates differ by type of institution, with both AACSB-accredited and doctoral-granting institution faculty publishing more than their counterparts at nonaccredited and non-doctoral-granting institutions. Specifically, while 74 percent of promoted faculty at doctoralgranting institutions had published at least one article in one of the top ten journals, only 25 percent from nondoctoral settings had done so. Similarly, only $60 \%$ of the associate professors promoted at non-accredited schools had published two or fewer articles by one year after their promotion, while 75 percent at accredited institutions had done so [Englebrecht et al., 1994, p. 51]. The parallel statistics for full professors are 50 percent and 90 percent, reflecting "the difference in publication activity required in various institutions" (p. 51).

According to Englebrecht et al., promoted faculty members at non-doctoral-granting institutions who do publish tend to publish in practitioner journals (p. 64). Glover et al. [both 2006 and 2012] investigate the publication records of accounting faculty at the top 75 accounting research institutions, revealing that "publication in top academic accounting journals is heavily concentrated in the highly ranked research universities" (p. 213). Christensen et al. [2002, p. 233] suggest that publication in non-accounting journals occurs somewhat later in accounting scholars' careers. Since the current article addresses the changing world of publication for senior scholars at institutions other than those concentrating in accounting research, these statistics go a good way towards explaining why we must pursue avenues for our investigative efforts that lie outside the realm of the top-tier scholarly publications, as elaborated below.

\section{The Proliferation of Outlets for Scholarly Work}

As part of this section on the changing world of publishing, the proliferation of outlets for scholarly work deserves attention, because it represents one of the biggest evolutions in the research environment. The expanded horizon of multiple outlets changes the entire landscape, and we sometimes feel as if we face a desert of shifting sands. Forced to choose among a variety of possible publication targets, we must address the pressing question: How will I know which journal will be viewed as highly ranked? Journals must earn their way into the "top" echelons, and once one publishes in the highly ranked journals, it becomes unclear just exactly what that means. In a 2004 article entitled "Is an Article in a Top Journal a Top Article?" Smith finds that citation statistics do not result in high classification accuracy; "top" articles are commonly rejected as such, and articles appearing elsewhere often are accepted as representing "top" articles. Chow et al. [2007] arrive at similar conclusions. Finally, Hermanson [2008, p. 60] notes that problems arise when expectations of research change abruptly and "suddenly one type of research is acceptable, and no other types of research count." This leads me to the next "new frontier" of scholarship, open access. 
In a 2012 article entitled, "The Inevitability of Open Access," Lewis presents open access as an alternative business model for publishing scholarly journals. In the article, he applies the concept of disruptive innovation (ascribed to business theorist Clayton Christensen, The Innovator's Dilemma: When New Technologies Cause Great Firms to Fail, 1997), contending that the industry of scholarly publication will be transformed by the technological changes embraced in open access. While scholars seek both access to the work of others and the prestige of publishing in highly-ranked subscription journals, they are able to avoid the monetary costs associated with the former as long as institutional support (library funding) remains available. But as subscription rates escalate, libraries become less and less able to maintain such access. With the proliferation of low-cost open access journals, a downward spiral for subscription-based journals ensues:

As Open Access grows, libraries will find the high prices of subscription journals harder to justify, and this will lead to cancellations. As subscription volumes fall, prices will need to rise; this will likely lead to further cancellations and still higher prices. This spiral will eventually make many subscription journals economically unsustainable. [Lewis, 503]

Through open access, the opportunities have never been greater for sharing one's scholarly products and one's general knowledge with those lacking the resources to tap into the ranked journals, and this begs the question: What new strategies might we employ to assure that our scholarly products reach all the "right ears"?

\section{Publication Strategies for the Future}

Now that so many avenues for disseminating our final products have opened up, we must consider carefully how we judge the worth of those choices. In other words, what does this world of journal proliferation and open access portend for us as engaged scholars? Three important questions surface: Is quality control threatened? Should we break the mold of scholarly publication? Is the current model unsustainable? Those of us beyond the threat of tenure denial must become engaged in the discussion of what constitutes the appropriate outlets for new work. In the world of online publication and open access, it becomes increasingly difficult to know which journals to target. But the bigger question is: Do I embrace the change to open access or defend against it on the basis that only top-tiered journals can assure the quality control of peer review to which we've become accustomed? I can't answer that question with statistics. But I believe panels of experts exist beyond those associated with the topranked journals in our fields. People who stay deeply engaged in their fields can serve as gatekeepers for new scholarship. No doubt, like much of human learning, we will experience a pendulum effect whereby some bad, possibly falsified, work will be published. But we will learn, we will become more critical, we will put devices in place to protect against plagiarism, dishonesty, and other human frailties that can threaten the quality of published scholarship. And the cream should rise.

The top-tier journals in finance and accounting offer superb scholarship, and I hold the authors in great esteem. I enjoying consuming the products of those journals and feed my students a steady diet of that work, so I think there will continue to be a market for such distinguished scholarship. But there is more cream to rise and more people who want to drink than are being served by the current system; the demand for outlets and the scholarship they might disseminate has been artificially constrained. Many more have something to say that is worth hearing; something to write that is worth reading. It simply falls outside the realm of scholarship embraced by top-tiered journals. Open access might just be the way to meet that need. So should we break the mold to encourage more widespread participation?

Some have taken a somewhat territorial approach to this "embrace or reject" question. In the accounting discipline, for example, Fogarty (2011) points to a fairly large body of literature that investigates the extensive influence a select few, primarily U.S., universities have over what and who gets published in the top-ranked accounting journals. He contends that the advice given to doctoral students plays a significant role in socializing certain behaviors that lead to a narrowing of research agendas. The discipline is governed through specific mechanisms and the author warns young researchers with a healthy dash of sarcasm, as indicated by some of Fogerty's subtitles (with brief summaries provided in brackets): 
- Disguising the Unlevel Playing Field [This advice cautions would-be scholars about the "formula" for determining the acceptability of work.]

- $\quad$ Knowing Ones' Place [Doctoral students are conditioned for a rough ride.]

- Whose Relevance Is It? [Only contemporary, "hot" theories should provide the focus, and questions must be posed so that answers can be quantified; policy implications and practical applications are secondary.]

- $\quad$ Accepting the Hierarchy [The social order, dictated by top-ranking journals, must not be disturbed.]

- $\quad$ Self-Reproduction [Enforce the norms; do not stray from the assumed values.]

In the following quote, Fogarty offers a rather vitriolic summary of his major point:

The will necessary to hold the system in place creates rigidity and an intolerance that is inconsistent with true academic norms. Errors cannot be as readily admitted and corrected. Central values, such as blind review, often are compromised. Excessive secrecy surrounds the shepherding of ideas to publications. New areas that could be developed within the discipline lie fallow... The talents of many are not brought to their highest and best use, but instead must escape the discipline to be recognized. Ceteris paribus, accounting within the U.S. stagnates not by accident or by misfortune, but by the advice that is tantamount to the eating of our young. (p. 46)

The bottom line is that the system might be creating an exclusionary stance that could lead to its own demise or, perhaps more importantly, a posture that diminishes what scholarly efforts might otherwise achieve. Although the giants in the field of accounting (and other disciplines) have earned their notoriety, to best further the pursuit of knowledge, perhaps occasionally we should stand on the toes of giants rather than on their shoulders. In short, our publication strategies must adapt to incorporate a world with multiple layers of publication outlets.

Many contend that the business model of the academic publishing industry is broken. In a 2010 article in Academe, Eisenberg and Romero [p. 1] note three parallels between the publication and distribution of academic journals and the healthcare industry: "[B]oth are vital to any advanced society... we spend vast sums for their products and services... similar forces and dynamics drove these industries to a place beyond the reach of many people who need their products and services." The authors really contend that scholarship should be a public good. Of course, that would mean controlling an industry in which the overall operating profit margin in 2008 was in excess of $14 \%$ (and substantially higher for the top three publishers). The industry controls its profits through a combination of limiting the supply and exerting undue influence over the price. From our perspective as those trying to get work published, we are more familiar with the limited supply, but according to Eisenberg and Romero (p. 3 of the online version), subscription prices have risen 500\% since 1990, while the CPI increased by only $41 \%$ and "the expense ratio for publishing remained steady."

According to McGuigan and Russell [2010], these high profit margins reflect the bargaining power of publishers rather than cost pressures or high value-adding activities. At that time, the top three publishers accounted for $42 \%$ of all articles published, while none of the next 2000 accounted for more than a $3 \%$ share of the total market. With a product (scholarly work) provided virtually free of charge to the publishers and a built in demand for the product, both as we publish our own work and include the work of others in our investigations, publishers play the role as middlemen. Furthermore, libraries have very little bargaining power and cannot (or do not) negotiate prices down. Thus demand is inelastic, and publishers are the beneficiaries. The authors offer a number of solutions: Librarians should create buyer consortia; technology should be used to create more electronic publications; we must unbundle electronic and paper journals; we must support the open access movement. Of course, free, non-commercial, peer-reviewed scholarly journals can only succeed if high quality editorial review boards make the review process credible, faculty see these journals as valid sources for new knowledge and outlets in which they wish to publish their scholarly work, and the published work is accepted in the promotion and tenure process. Certainly this type of acceptance would represent a significant change in strategy.

In recent years, the Association to Advance Collegiate Schools of Business (AACSB) has broadened its scope of acceptable work to be included in reviews for accreditation. Its 2013 "Eligibility Procedures and Accreditation Standards for Business Accreditation" states that intellectual contributions must be "validated by peers and disseminated to appropriate audiences..." but adds that this validation "...includes the traditional academic or 
professional pre-publication peer review, but may encompass other forms of validation, such as online postpublication peer reviews..." (p. 16). In the section entitled "Guidance for Documentation," the AACSB lists not only journals but scholarly presentations, invited presentations, and even teaching materials. Those of us who belong to institutions in which solid teaching is accented know that most top-tier publications accept fewer pedagogical than empirical submissions, and our portfolios include more of these three types of proof of scholarly effort. To that end, the AACSB encourages schools seeking accreditation or reaccreditation to emphasize and describe how the scholarship produced relates to the mission of the school and to make that link transparent, both internally and to the public. Again, our publication strategies must address this important aspect.

Taking a more ethics-based stance on the current state of academic publication, Dan Cohen, Associate Professor of History at George Mason University and Director of the Roy Rosenzweig Center for History and New Media, holds that we should be ashamed of our resistance to the move to open access on a number of levels, not the least of which is intellectual snobbery. In an entry posted in Academia (and two other on-line sites, May 27, 2010), he advises us to be impartial in our approach to creative works and to avoid looking to others to judge the value of new works; we must "honor creativity and quality," and "reorient ourselves to our true core value." He chides us: "If you're publishing primarily for careerist reasons and don't deeply care about your subject matter, let me recommend you find another career." Finally, when we defend the bastions of expensive journals as the only outlet for our work, Cohen invokes our guilt reflex, saying, "We professors care less about sharing our work—even with underprivileged nations that cannot afford access to gated resources - than with making sure we impress our colleagues." Thus the current state of academic scholarship endures yet another scolding, an indication that our strategy for sharing our intellectual contributions must adapt. So what are we to take away from all this?

\section{What Actions Should Senior Scholars Take?}

Some of the preceding research offered a number of steps for senior scholars-not simply steps to improve our own research habitat but steps that will set a new stage for our younger peers. Help your library staff in the creation of library consortia; embrace the use of technology to publish electronically; unbundle the very different products of electronic and paper journals; support the open access movement by ensuring high quality review and credibility and recognizing these journals as valid. Spend some time being a "gatekeeper" for these new publication outlets; volunteer for editorial staffs, read works, and produce ones of your own. And, most importantly, work within your institution and your field to make the scholarly products acceptable in the tenure and promotion processes. After all, as tenured members of our departments, we have the freedom to support this brave new world - and we can grow in the process. Furthermore, a compelling argument can be made on the basis of the new AACSB standards for counting journal publications for accreditation purposes. This agency now looks for the impact of specific articles, regardless of publication outlet. One need not target top-tier journals only, as online, open access journals can do a great job of tracking downloads and citations.

The current article set out to address several questions - why research; what mechanisms are available to share that work; what changes should make us think differently about our scholarship and how it is circulated; how can we participate in future developments? You have read one senior faculty member's view of the value of research, witnessed the unbridled charm of Fogerty claiming that we "eat our young," received an invitation to work with your librarian to usher in the new world of open access, been chastised by Cohen, who encourages us to share our milk and cookies more freely, looked at some of the obstacles senior faculty at non-research institutions face in top-tier publishing, and received an array of possible steps to take. The world is already changing, and I strongly recommend that you familiarize yourself with the article by Lewis cited in an earlier section. So the answer to the question posed in the title to the current work is a resounding "Yes!" My advice includes the following: Find a way to participate actively; don't just let it happen. Trust your instincts; be vigilant in assessing what's out there, but be willing to open new doors. Don't compromise-do your best work (always good advice, regardless of the occasion). Go forth and be enlightened. Enlighten others - and do so through all available channels.

\section{AUTHOR INFORMATION}

Judy Laux is the Bill Barton Professor of Economics and Business at Colorado College, teaching and researching in the areas of accounting and finance. E-mail: jlaux@coloradocollege.edu 


\section{REFERENCES}

Association to Advance Collegiate Schools of Business. 2013. "Eligibility Procedures and Accreditation Standards for Business Accreditation." AACSB, www.aacs.edu/AACSBBusinessAccreditation, accessed 10/14/14.

Brice, Julie and John Bligh. 2004. “Author Misconduct: Not Just the Editors' Responsibility." Medical Education, Vol. 39: 83-89.

Boyer, Ernest L. 1990. "Scholarship Reconsidered: Priorities of the Professoriate." A Special Report. TheCarnegie Foundation for the Advancement of Teaching.

Chow, Chee W., Kamal Haddad, Gangaram Singh, and Anne Wu. 2007. "On Using Journal Rank to Proxy for an Article's Contribution or Value." Issues in Accounting Education. Vol. 22, No. 3: 411-427.

Christensen, A. L., C.A. Finger, and C.K. Latham. 2002. "New Accounting Scholars' Publications in Accounting and Nonaccounting Journals. Issues in Accounting Education Vol. 17, No. 3: 233-251.

Christensen, Clayton. 1997. The Innovator's Dilemma: When New Technologies Cause Great Firms to Fail. Harvard Business School Press Books, April.

Cohen, Dan. 2010. “Open Access Publishing and Scholarly Values.” Academia. Posted May 27, 2010.

Eisenberg, Barry and Lisa Romero. 2010. "Restoring the Health of Scholarly Publishing." Academe. Vol. 96, Issue 5: 38-43.

Englebrecht, T.D., G.S. Iyer, and D.M. Patterson. 1994. "An Empirical Investigation of the Publication Productivity of Promoted Accounting Faculty." Accounting Horizons Vol. 8, No. 1: 45-68.

Fogerty, Timothy J. 2011. "The Social Construction of Research Advice: The American Accounting Association Plays Miss Lonelyhearts." Accounting and the Public Interest. Vol. 11: 21-51.

Glover, S.M., D.F. Prawitt, and D.A. Wood. 2006. "Publication Records of Faculty Promoted at the Top 75 Accounting Research Programs. Issues in Accounting Education 21 (August): 195-218.

Glover, S.M., D.F. Prawitt, S.L. Summers, and D.A. Wood. 2012. "Publication Benchmarking Data Based on Faculty Promoted at the Top 75 U.S. Accounting Research Institutions." Issues in AccountingEducation. Vol. 27, Issue 3: 647-670.

Hasselback, J.R., A. Reinstein, and E.S. Schwan. 2003. "Prolific Authors of Accounting Literature." Advances in Accounting 20: 95-125.

Henson, K.T. 2001. "Writing for Professional Journals: Paradoxes and Promises." The Phi Delta Kappan. Vol. 82, No. 10: 765-768.

Hermanson, Dana R. 2008. "What I Have Learned So Far: Observations on Managing an Academic Accounting Career." Issues in Accounting Education. Vol. 23, No. 1: 53-66.

LaPidus, Jules B. 1998. "Scholarly Research: Oxymoron, Redundancy, or Necessity?" Academies Press, National Research Council (US) Chemical Sciences Roundtable.

Laux, Judith A. 2013. "Scholarship and the Academic 'Lifer." Proceedings of the 2013 Clute Institute International Academic Conference.

Lewis, David W. 2012. "The Inevitability of Open Access." College \& Research Libraries. September: 493-506.

McGuigan, Glenn S. and Robert D. Russell. 2008. "The Business of Academic Publishing: A Strategic Analysis of the Academic Journal Publishing Industry and its Impact on the Future of Scholarly Publishing." Electronic Journal of Academic and Special Librarianship. Vol. 9, No. 3.

Parco. James. 2013. "Research Principles and Goals." From the third-year review file. Colorado College.

Smith, Stanley. 2004. "Is an Article in a Top Journal a Top Article?" Financial Management. Winter: 133-149.

Spooner, Melba; Fred Spooner, and Meagan Karvonen. 2002. "Contributing to the Profession in Meaningful Ways." Action in Teacher Education. Vol. 24, Issue 3: 10-19.

Swanson, E.P. 2004. "Publishing in the Majors: A Comparison of Accounting, Finance, Management, and Marketing”. Contemporary Accounting Research Vol. 21, No. 1: 223-255.

Zivney, T.L., W.J. Bertin, and T.A. Gavin. 1995. "A Comprehensive Examination of Accounting Faculty Publishing." Issues in Accounting Education Vol. 10, No. 1: 1-25. 